\title{
Influence of Hydrostatic Extrusion on the Mechanical Properties of the Model Al-Mg Alloys
}

\author{
Aleksandra Towarek (iD, Wojciech Jurczak, Joanna Zdunek, Mariusz Kulczyk, and Jarosław Mizera
}

\author{
Submitted: 9 October 2020 / Revised: 10 February 2021 / Accepted: 28 February 2021 / Published online: 25 March 2021
}

\begin{abstract}
Two model aluminium-magnesium alloys, containing 3 and $7.5 \mathrm{wt} \%$ of $\mathrm{Mg}$, were subjected to plastic deformation by means of hydrostatic extrusion (HE). Two degrees of deformation were imposed by two subsequent reductions of the diameter. Microstructural analysis and tensile tests of the materials in the initial state and after deformation were performed. For both materials, HE extrusion resulted in the deformation of the microstructure-formation of the un-equilibrium grain boundaries and partition of the grains. What is more, HE resulted in a significant increase of tensile strength and decrease of the elongation, mostly after the first degree of deformation.
\end{abstract}

Keywords aluminium alloys, Al-Mg, hydrostatic extrusion, plastic deformation

\section{Introduction}

Aluminium alloys of the $5 \mathrm{xxx}$ series, containing major addition of magnesium are often the first-choice material in multiple constructions of the shipbuilding industry. They owe it to the outstanding resistance to corrosion in sea water and sea atmosphere, combined with an improved mechanical strength, when compared to other Al-alloys (Ref 1-3). What is of particular importance, due to their low density and corrosion resistance $\mathrm{Al}-\mathrm{Mg}$ alloys allow a significant reduction of the fuel and maintenance costs (Ref 4). However, their use is limited to the structures which do not carry extensive loads, for their strength is not sufficient (Ref 1, 3). In order to improve their mechanical properties, methods of large and severe plastic deformation are commonly used (Ref 5-8).

The effectiveness of the plastic deformation methods in improving the strength of Al-Mg alloys is described in the literature, mostly on the example of high pressure torsion (HPT) (Ref 9, 10) and equal channel angular pressing (ECAP) (Ref 6, $11,12)$ techniques. The strengthening effect is usually attributed to the grain refinement (Ref 10,13 ), increased density of dislocations (Ref 9, 14, 15), deformation of the microstructure leading to the formation of subgrains, deformation bands, stacking faults or non-equilibrium grain boundaries (Ref 10, 16-18) and presence of $\mathrm{MgO}$ nanodispersoids (Ref 19).

Hydrostatic extrusion (HE) is a less commonly used method of imposing large plastic deformation. It engages the hydrostatic pressure for the extrusion of material in the form of a rod through

Aleksandra Towarek, Joanna Zdunek, and Jarosław Mizera Faculty of Materials Sciences and Engineering, Warsaw University of Technology, Warsaw, Poland; Wojciech Jurczak, Faculty of Mechanical and Electrical Engineering, Polish Naval Academy, Gdynia, Poland; Mariusz Kulczyk, Institute of High Pressures Physics UNIPRESS, Polish Academy of Sciences, Warsaw, Poland. Contact e-mail: aleksandra.towarek.dokt@pw.edu.pl. the die. It results in the reduction of the rod's diameter and plastic deformation of the material $(\operatorname{Ref} 20)$. The triaxial state of stresses imposed during the process results in certain assets of the method, such as the homogeneity of deformation, high strain rates in single pass and low friction, which allow to process even brittle and hard-to-deform materials (Ref 21, 22). It was also observed that almost adiabatic conditions maintained during $\mathrm{HE}$ process result in the generation of heat, therefore thermally activated processes such as recovery and recrystallization may occur, particularly in materials with high SFE (Ref 23).

However, despite the growing interest in the HE and its potential, there are not many studies on the application of this method for processing of $\mathrm{Al}$ and $\mathrm{Al}-\mathrm{Mg}$ alloys in particular. Kulczyk at al reported that HE of pure Al with the true strain reaching 6 resulted in an increase of yield strength by almost $140 \%$ (Ref 24). Al-Mg alloys from the 5xxx series have been examined by Zdunek et al.(Ref 25). They observed a significant grain refinement resulting in an increase of the microhardness and mechanical properties of 5483 alloy after HE with the true strains equal to $1.4,2.8$ and 3.8. More results have been published on the influence of $\mathrm{HE}$ on the $6 \mathrm{xxx}$ series of $\mathrm{Al}$ alloys. All of them indicate that $\mathrm{HE}$ resulted in the grain refinement and improvement of properties such as microhardness and strength, without deteriorating properties such as ductility and electrical conductivity (Ref 23, 26-30). Pakieła et al. (Ref 21) summarized the impact of HE on the mechanical properties of several types of Al alloys, and a significant improvement was noticed in all analysed materials.

Therefore, the aim of this study will be to determine the influence of the hydrostatic extrusion on the mechanical properties of the Al-Mg (5xxx series) alloys. The impact in the study will be put on the correlation between the amount of magnesium, deformation degree and the strengthening of the processed materials. The results will also be discussed in terms of the microstructural evolution of the materials.

\section{Materials and Methods}

Two model aluminium alloys with different amounts of magnesium were chosen for the research. The first alloy, described as $\mathrm{AlMg} 3$ — containing 3 wt. \% of Mg, amount similar 
to many typically used commercial $\mathrm{Al}$ alloys from $5 \mathrm{xxx}$ series (Ref 31). The second alloy, described as AlMg7.5-with the addition of $7.5 \mathrm{wt} \%$ of $\mathrm{Mg}$. The choice of the alloy with enhanced amount of magnesium was dictated by the available literature proving a positive correlation between the amount of magnesium and the strain hardening ability of the Al-Mg alloys (Ref 19, 32, 33).

The alloys were manufactured by casting into the form of rods with 20-mm-diameter and subsequently homogenised. Complete composition of the alloys is given in Table 1. Both alloys were further subjected to hydrostatic extrusion using a Hydrostatic Extrusion Press in the Institute of High-Pressure Physics "Unipress" Institute Polish Academy of Sciences in Warsaw. The process was held with the operating pressure of about $1 \mathrm{GPa}$ at the room temperature. Deformation was held in two steps, as illustrated in the Fig. 1. In the first step rods' diameter was reduced up to $13 \mathrm{~mm}$, and in the latter, it was further reduced to $10 \mathrm{~mm}$. This resulted in the deformation degrees $\varepsilon 1=0.9$ and $\varepsilon 2=1.4$, respectively. The experimental details of hydroextrusion process are shown in Table 2. Materials in the initial state and after each step of deformation were further analysed and will be denoted as IS, $\varepsilon 1$ and $\varepsilon 2$, respectively. Figure 2 shows the characteristics of the $\mathrm{HE}$ process obtained for both alloys during the first step of deformation and after the complete process. In the initial phase of the HE process, an increase in pressure is observed, associated with compressing the pressure medium in the working chamber to a value that allows the process of the material's plastic flow to start. The pressure peak is associated with the commencement of material flow and the change of static to kinetic friction followed by stabilization of the extrusion pressure and material outflow at a constant extrusion rate. Obtaining a constant extrusion speed is important for the homogeneity of physical and mechanical properties over the length of the extruded product.

Samples for the microstructural examination were cut from the rods in the direction transverse to the HE direction. They were mounted in resin, grinded, polished and etched electrochemically with the use of Barker etchant $\left(4 \% \mathrm{HBF}_{4}\right.$ in $\left.\mathrm{H}_{2} \mathrm{O}\right)$. They were observed with the use of optical microscope (OM) in the cross polarized light. Subsequently, the materials were subjected to observations with the use of STEM microscope in the transmission mode. Samples for this examination had a form of thin foils, obtained by electropolishing in the solution of nitric acid in methanol. Tensile tests were performed to determine the mechanical properties of the materials. Measure-

Table 1 Complete chemical composition of the examined alloys

\begin{tabular}{lllllllllllll}
\hline [wt.\%] & Fe & Si & $\mathbf{C u}$ & $\mathbf{Z n}$ & $\mathbf{T i}$ & $\mathbf{M n}$ & $\mathbf{M g}$ & $\mathbf{N i}$ & $\mathbf{C r}$ & $\mathbf{P b}$ & $\mathbf{B e}$ & $\mathbf{A l}$ \\
\hline AlMg3 & 0.096 & 0.076 & 0.007 & 0.005 & 0.004 & 0.004 & 3.06 & 0.006 & 0.001 & 0.001 & 0.006 & 96.73 \\
AlMg7.5 & 0.16 & 0.08 & 0.001 & $\ldots$ & 0.016 & 0.006 & 7.52 & 0.002 & $\ldots$ & 0.003 & $\ldots$ & 92.21 \\
\hline
\end{tabular}

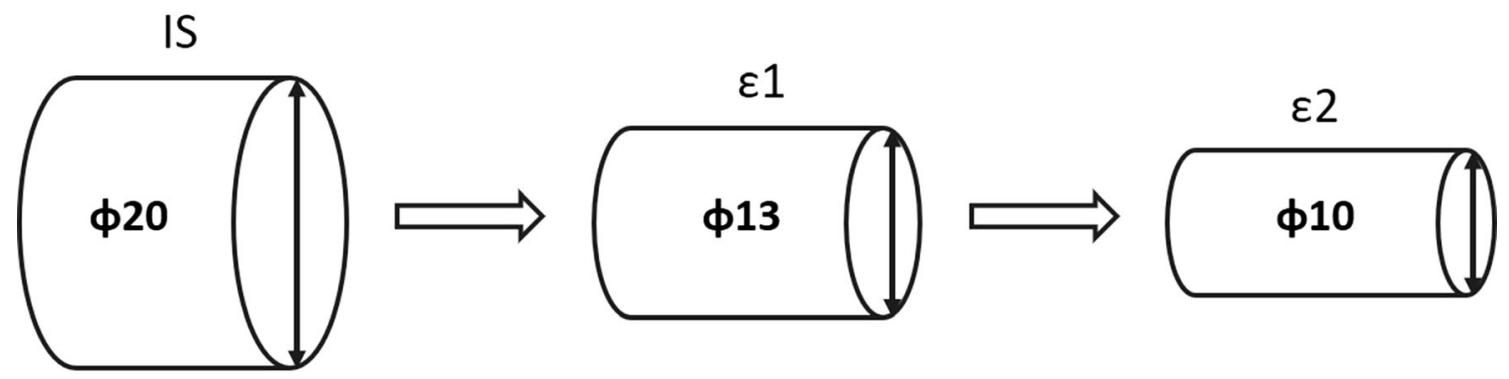

Fig. 1. Illustration of the material deformation after both steps of hydrostatic extrusion

Table 2 The experimental data of the hydrostatic extrusion process

\begin{tabular}{|c|c|c|c|c|c|c|c|c|c|}
\hline & $\begin{array}{c}\text { Initial } \\
\text { diameter } d_{\mathbf{o}} \\
\mathbf{m m}\end{array}$ & $\begin{array}{c}\text { Final } \\
\text { diameter } \\
d_{\mathrm{f}}, \mathbf{m m}\end{array}$ & $\begin{array}{l}\text { Reduction } \\
R\left(d_{0}{ }^{2} / d_{\mathrm{f}}{ }^{2}\right)\end{array}$ & $\begin{array}{c}\text { Cumulative } \\
\text { reduction } \\
\boldsymbol{R}_{\text {cum }}\end{array}$ & $\begin{array}{c}\text { True } \\
\text { strain e } \\
(\ln R)\end{array}$ & $\begin{array}{c}\text { Cumulative } \\
\text { true strain } \\
e_{\text {cum }}\end{array}$ & $\begin{array}{c}\text { Linear } \\
\text { speed, mm/ } \\
\text { sec }\end{array}$ & $\begin{array}{l}\text { Strain } \\
\text { rate, } \mathbf{s}^{-1}\end{array}$ & $\begin{array}{c}\text { Extrusion } \\
\text { pressure } p_{\mathrm{HE}} \\
\mathrm{MPa}\end{array}$ \\
\hline $\begin{array}{l}\mathrm{AlMg} 3 \\
\quad \varepsilon 1\end{array}$ & 20 & 13 & 2.37 & 2.37 & 0.86 & 0.86 & 66.27 & $2.32 \mathrm{E}+00$ & 284 \\
\hline $\begin{array}{l}\mathrm{AlMg} 3 \\
\varepsilon 2\end{array}$ & 13 & 10 & 1.69 & 4 & 1.39 & 2.25 & 112.00 & $8.45 \mathrm{E}+00$ & 264 \\
\hline $\begin{array}{l}\mathrm{AlMg} 7.5 \\
\quad \varepsilon 1\end{array}$ & 20 & 13 & 2.37 & 2.37 & 0.86 & 0.86 & 66.27 & $2.32 \mathrm{E}+00$ & 397 \\
\hline $\begin{array}{l}\mathrm{AlMg} 7.5 \\
\quad \varepsilon 2\end{array}$ & 13 & 10 & 1.69 & 4 & 1.39 & 2.25 & 112.00 & $8.45 \mathrm{E}+00$ & 375 \\
\hline
\end{tabular}



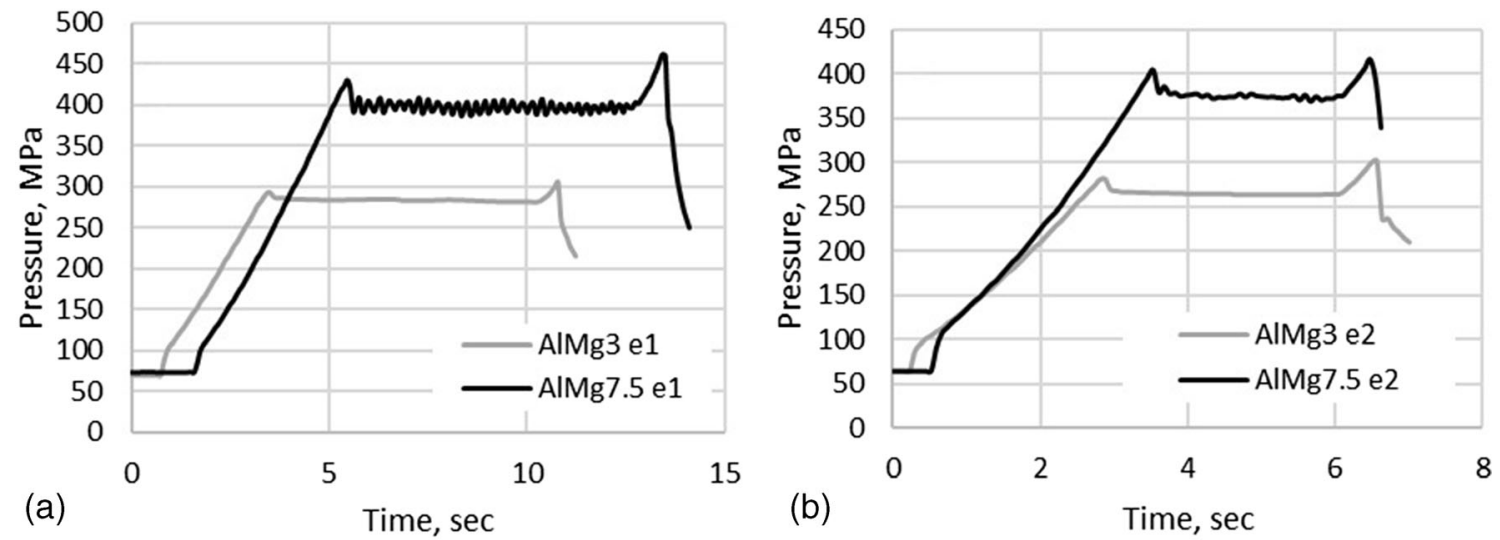

Fig. 2 Characteristics of the hydrostatic extrusion $\mathrm{HE}$ of $\mathrm{AlMg} 3$ and $\mathrm{AlMg} 7.5$ alloys after (a) one step and (b) cumulative HE

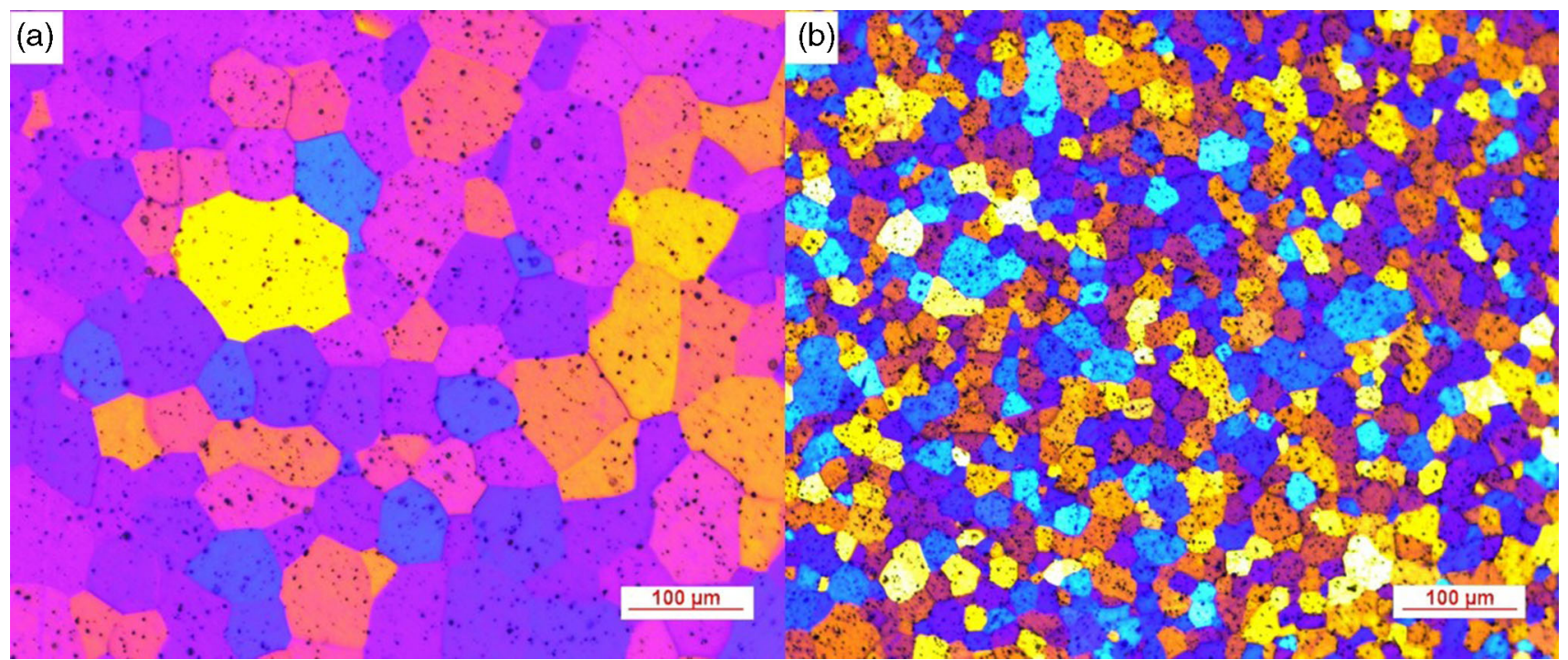

Fig. 3 OM images of (a) AlMg3 and (b) AlMg7.5 IS microstructures

ments were held in the room temperature, using a strain rate of $2.7 \times 10^{-3} \mathrm{~s}^{-1}$ on an MTS 810 machine. Maximal tensile strength $\left(R_{\mathrm{m}}\right)$ and maximal elongation $\left(\mathrm{A}_{5}\right)$ were obtained from the analysis.

\section{Results and Discussion}

\subsection{Microstructures}

Analysed materials in the initial state (Fig. 3a and b) have coarse grained microstructures with average grain sizes approx. $50 \mu \mathrm{m}$ for the AlMg3 and approx. $20 \mu \mathrm{m}$ for the AlMg7.5. Both microstructures are single-phased and uniform. Grains in the AlMg7.5 are more homogeneous, in contrary to the AlMg3 where large differences in grain sizes can be noticed. Grains in both alloys are relatively equiaxial with elongation coefficients equal 1.4 for the AlMg3 and 1.35 for the AlMg7.5.

After HE process, the microstructures change significantly. For both materials after the first step of deformation (Fig. 4a and b), grains become irregular, misshapen with less clear grain boundaries. This step of deformation does not result in the decrease of the grain size. Despite the fact that it was impossible to measure the grain size for those structures, due to their complication and unclear grain boundaries, similarity of their diameters to the IS can be assumed from the pictures. After the second degree of HE, transformations of microstructure become more visible and intensive, resulting in the more irregular grain shapes and grains split into parts (Fig. 5a and b). The poorly defined and unclear grain boundaries are supposedly the non-equilibrium grain boundaries, often present in the deformed alloys (Ref 34). They occur as the result of the internal stresses caused by the increasing density of dislocations within the grain boundaries (Ref 35). The lamellar- like structures can also be notices within the grains of all observed samples after deformation. They are identified as deformation bands or subgrains that show up at the grain boundaries at the early stages of deformation (Ref 17, 36). In the initial state, the differences between the grain size can be explained with the magnesium atoms slowing down the solidification process and promoting the nucleation of new grains, therefore leading to the stronger refinement of the microstructure (Ref 37). However, it is also known that the difference of grain sizes between the alloys can be attributed to the values of stacking fault energy, 


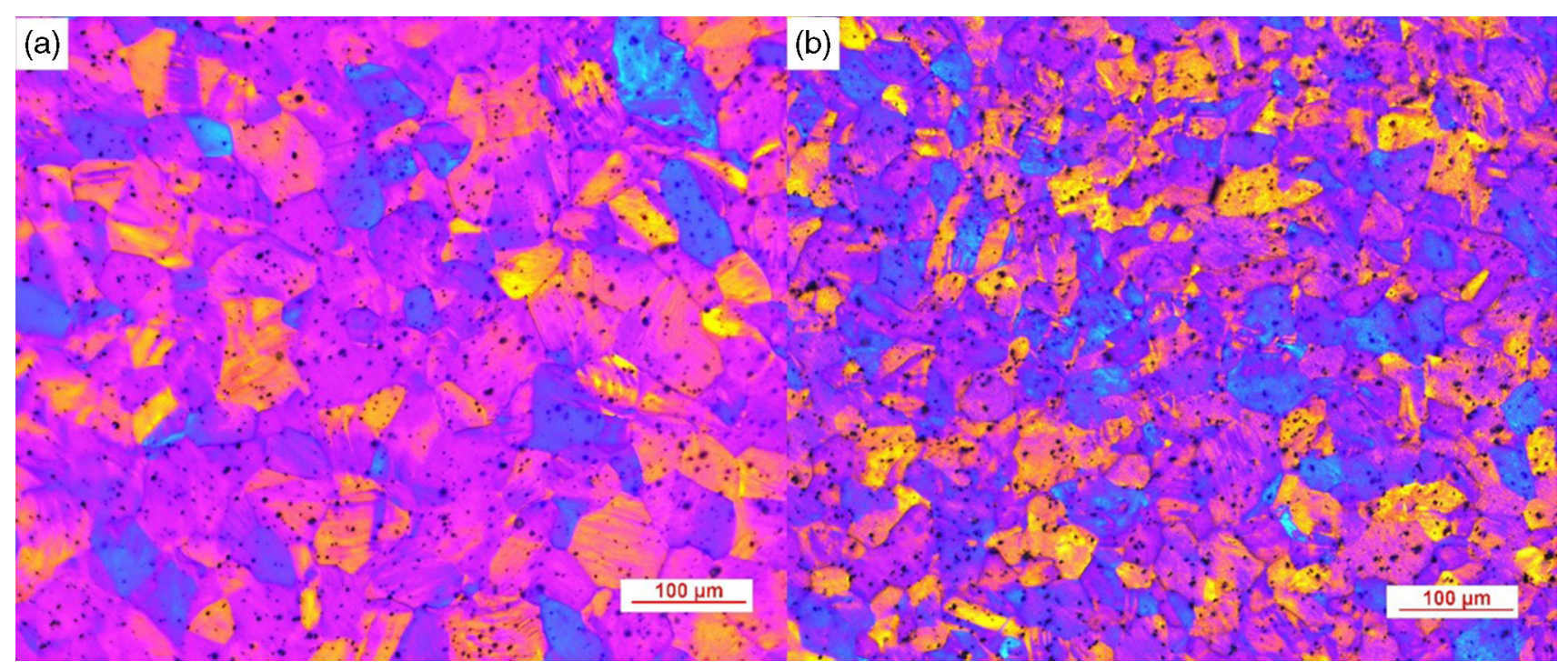

Fig. $4 \mathrm{OM}$ images of (a) AlMg3 and (b) AlMg7.5 $\varepsilon 1$ microstructures

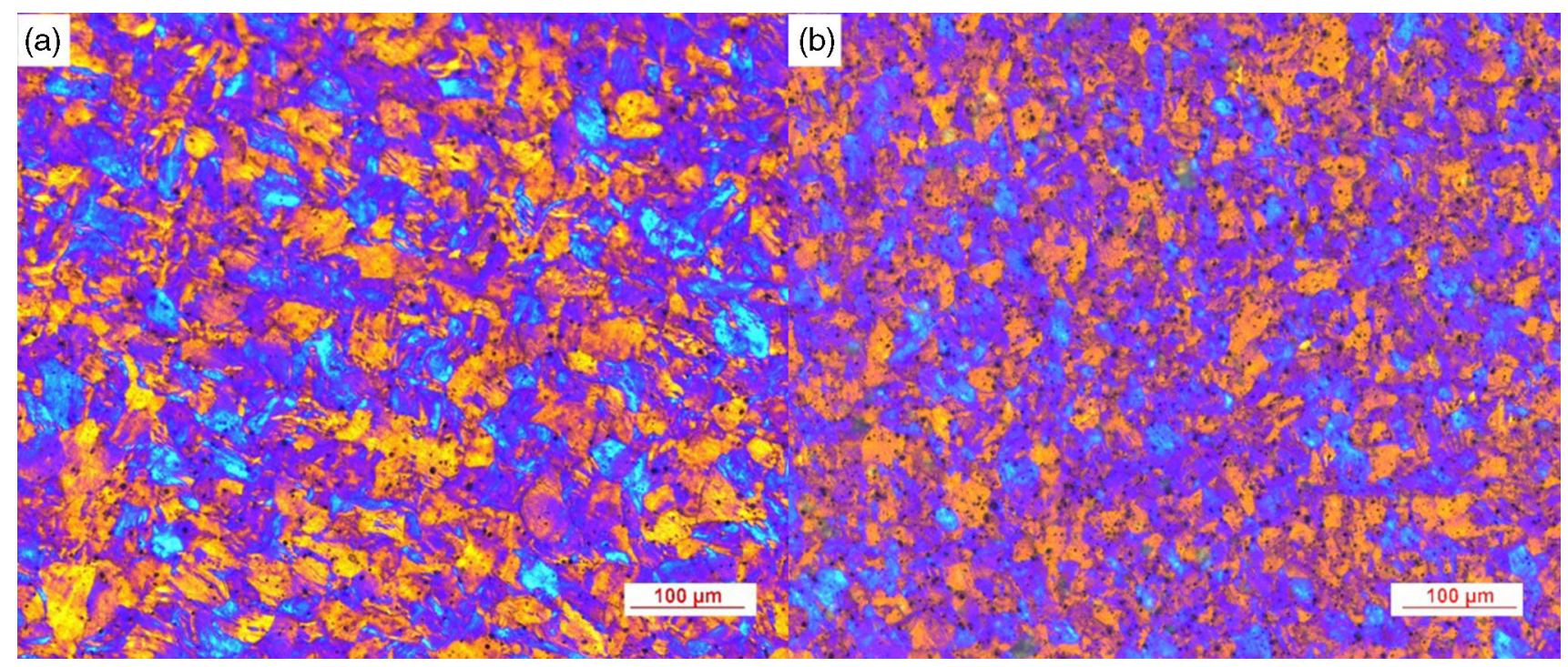

Fig. $5 \mathrm{OM}$ images of (a) $\mathrm{AlMg} 3$ and (b) $\mathrm{AlMg} 7.5$ \&2-microstructures

which decreases with the increasing amount of magnesium. It restrains the recovery of the microstructure during deformation and allows maintaining the fine grains (Ref 38, 39).

Observations in the transmission mode allowed a deeper analysis of the microstructural transformations in the examined alloys. In the AlMg3 alloy, in the initial state only grain boundaries and a moderate amount of dislocations can be noticed (Fig. 6a). According to the equilibrium phase diagram, the amount of magnesium in this alloy is a threshold value for the formation of $\beta$ particles. However, research claims that it is not sufficient for the precipitation process to occur regardless the duration of ageing treatment and that $\beta$ phase does not form (Ref 40). The AlMg7.5 alloy in the IS reveals a structure similar to the AlMg3 IS with grain boundaries and a remote number of dislocations (Fig. 6b). In this alloy, segregation of magnesium to the grain boundaries can be noticed. It takes a form of elongated darker areas along the grain boundaries.
After the first degree of deformation, both alloys reveal highly undeveloped microstructures (Fig. 7a and b). Concentration of dislocations in the vicinity of primary grain boundaries can be noticed. Dislocations tangle and arrange into clusters with preferred orientations, locally substructures and single new grains are being formed. In the AlMg7.5 alloy, precipitations of $\beta$ phase located along the grain boundaries and at the triple points are also present.

Second degree of deformation results in the further increase of dislocations' amount and more intensive creation of the substructures. Lamellar-like substructures or deformation bands are clearly visible, the amount of new grains increases. $\beta$ phase particles are also observed along the grain boundaries in the AlMg7.5 alloy (Fig. 8 and 9).

Development of the microstructural transformations is more intensive in the AlMg7.5 alloy after both degrees of deformation. Its lower value of SFE can be used to explain this 


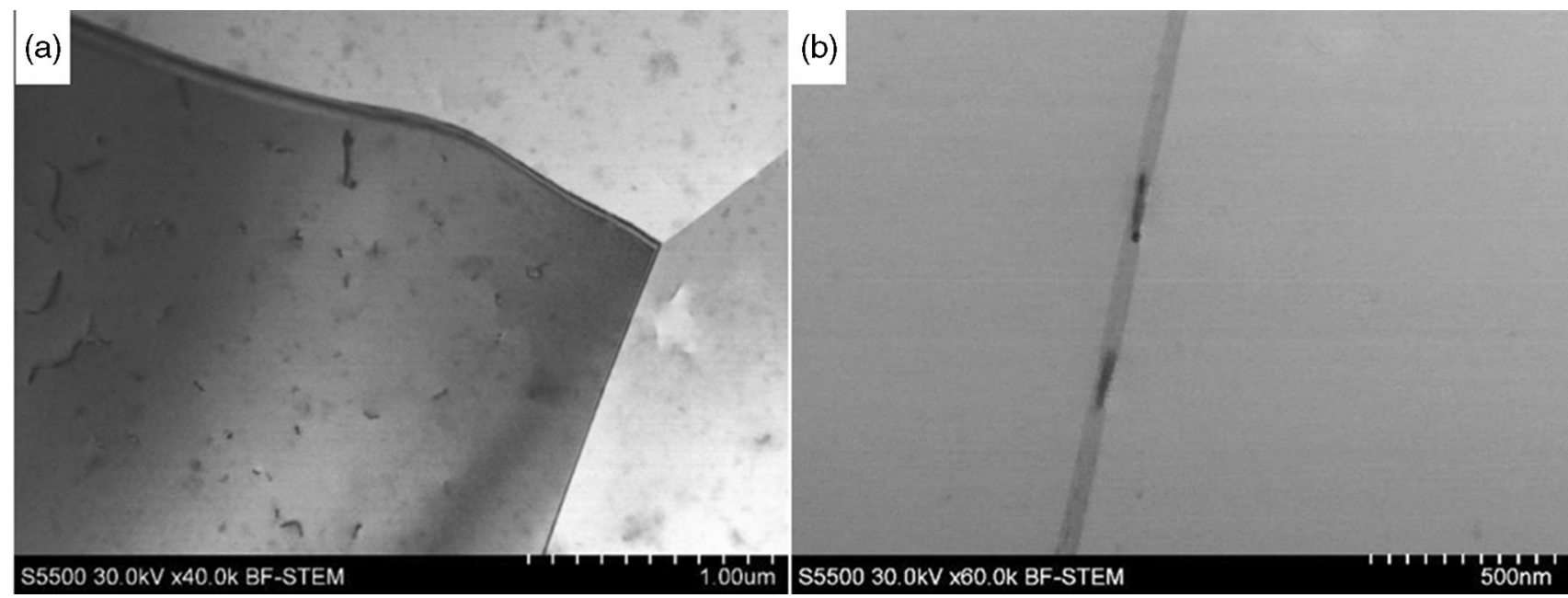

Fig. 6 STEM images of (a) AlMg3 and (b) AlMg7.5 IS microstructures

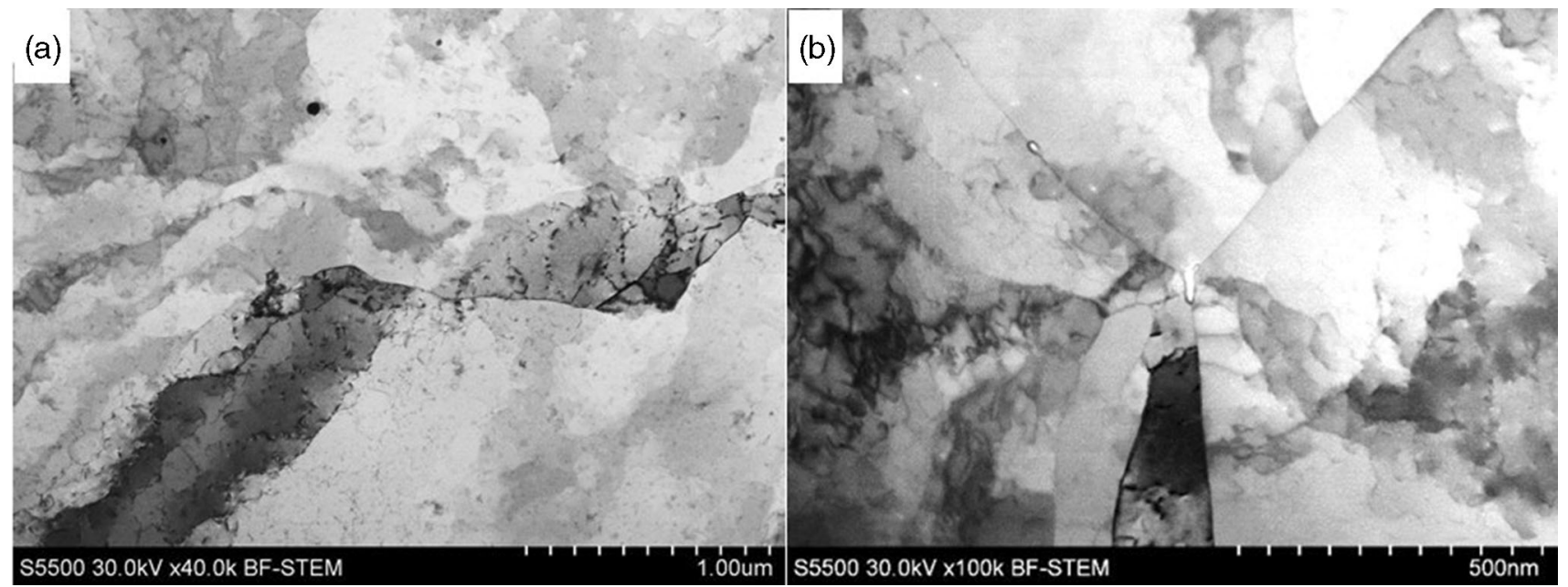

Fig. 7 STEM images of (a) AlMg3 and (b) AlMg7.5 $\varepsilon 1$ microstructures

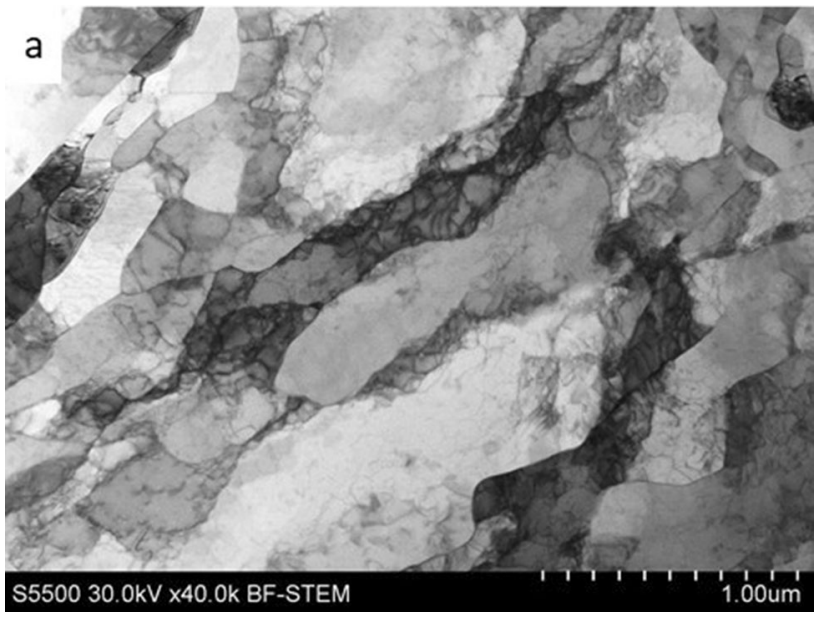

Fig. 8 STEM image of AlMg3 $\varepsilon 2$ microstructure phenomenon, for it results in the limitation of the cross-slip and promotes dislocation tangling and formation of deformation bands instead (Ref 37, 41-43). This eventually leads to the more effective rearrangement of the microstructure during the process of deformation (Ref 5).

\subsection{Tensile Properties}

Stress-strain curves for both alloys show large differences between the initial and deformed state (Fig. 10 and 11). However, the curves for the samples after the first and second step of the HE process are similar within each alloy. As expected from the strengthening potential of magnesium in Al$\mathrm{Mg}$ alloys (Ref 44, 45), the maximum strength of the AlMg7.5 in the initial state is significantly higher than in the AlMg3 IS (340 and $200 \mathrm{MPa}$, respectively). In both alloys deformation resulted in a large increase of maximal strength, approximately $60 \%$ for the AlMg3 alloy and almost 50\% for the AlMg7.5 (Fig. 12). On the basis of microstructural analysis and literature, 

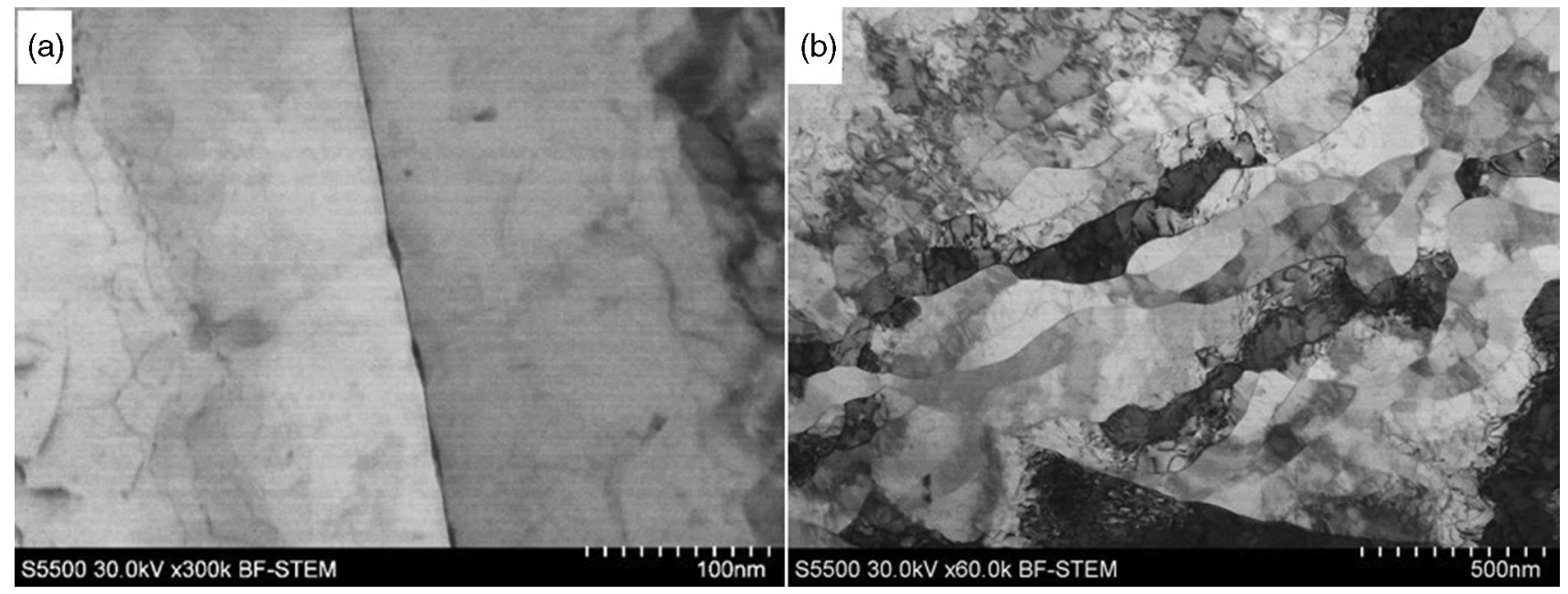

Fig. 9 STEM images of AlMg7.5 $\varepsilon 2$ microstructure
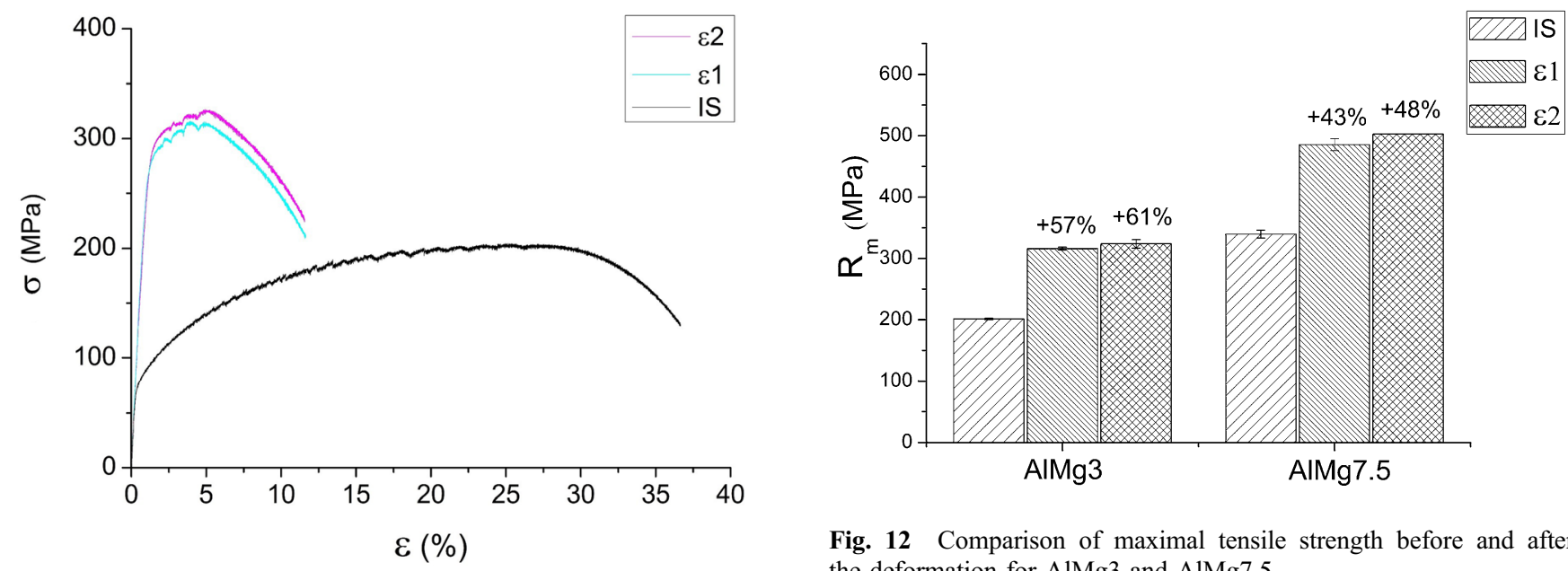

Fig. 10 Stress-strain curves for AlMg3 in initial state and after hydrostatic extrusion

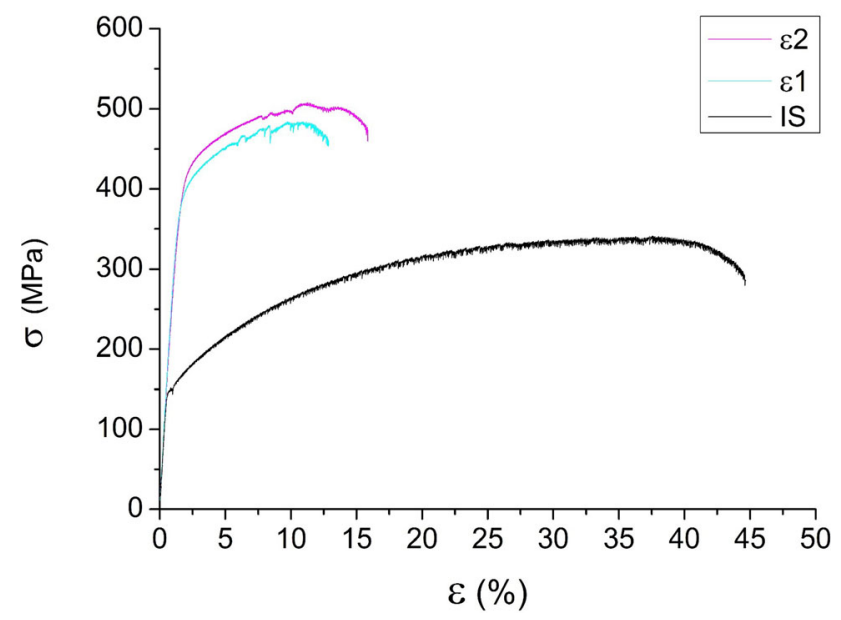

Fig. 11 Stress-strain curves for AlMg7.5 in initial state and after hydrostatic extrusion

Fig. 12 Comparison of maximal tensile strength before and after the deformation for $\mathrm{AlMg} 3$ and $\mathrm{AlMg} 7.5$

it can be assumed that the increased amount of dislocations, their interactions with solute $\mathrm{Mg}$ atoms and formation of the substructures are main factors responsible for the strengthening effect in the deformed alloys. However, it should be noticed that there is a very low difference of strength improvement between the two stages of deformation for both alloys. The first stage of deformation results in the intensive strengthening, while after the second stage, relative strength increases for additional 4 or 5 percentage points only. The same tendency has been observed by Zdunek et al (Ref 46). It can be explained with the fact that microstructural alterations between both degrees of deformation are much less significant when compared to the undeformed material.

When the plasticity of the materials is considered, HE leads to the large decrease of the elongation for both materials. The tendency is analogical to the strengthening (Fig. 13) - the effect is very intensive after the first stage of deformation, while the changes after the second stage are minimal or none. Decrease of plasticity is observed that is most aluminium alloys subjected plastic deformation and is the result of the same mechanisms that govern the strengthening of the material. 


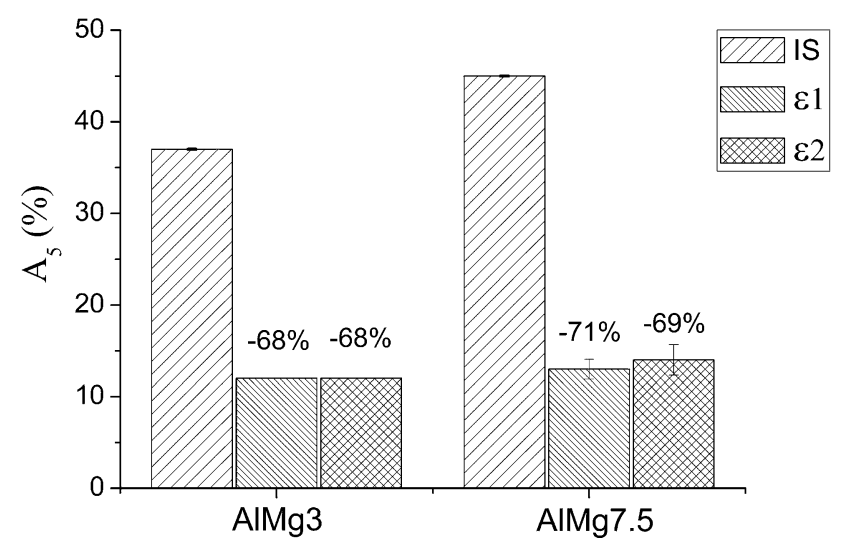

Fig. 13 Comparison of maximal elongation before and after the deformation for $\mathrm{AlMg} 3$ and $\mathrm{AlMg} 7.5$

\section{Conclusions}

The effect of hydrostatic extrusion on the microstructure and tensile properties of the model $\mathrm{Al}-\mathrm{Mg}$ alloys was analysed. Influence of the deformation degree and the amount of magnesium was observed. It can be concluded that:

- Deformation of the fully-developed equiaxial microstructures is observed in both alloys after HE. After the first step of HE an increased density of dislocations, locally formed substructures and newly formed grains are present. The second step of deformation brings a minor intensification of the microstructural transformations

- A significant improvement of the maximal tensile strength occurred after the first step of HE, at the same time the elongation was drastically decreased. The second degree of deformation did not bring any significant alterations in the mechanical parameters.

- The true strains imposed during the process of HE in this research were relatively low, when compared to the literature [e. g. (Ref 5, 12, 28, 47, 48)]. However, significant increase of strength was obtained in both alloys. Hence, this method has a potential to be considered an attractive alternative for the commonly used methods of large plastic deformation.

\section{Open Access}

This article is licensed under a Creative Commons Attribution 4.0 International License, which permits use, sharing, adaptation, distribution and reproduction in any medium or format, as long as you give appropriate credit to the original author(s) and the source, provide a link to the Creative Commons licence, and indicate if changes were made. The images or other third party material in this article are included in the article's Creative Commons licence, unless indicated otherwise in a credit line to the material. If material is not included in the article's Creative Commons licence and your intended use is not permitted by statutory regulation or exceeds the permitted use, you will need to obtain permission directly from the copyright holder. To view a copy of this licence, visit http://creativecommons.org/licenses/by/4.0/.

\section{References}

1. S. Ferraris, and L. M. Volpone, Aluminum Alloys in Third Millennium Shipbuilding: Materials, Technologies, Persepectives, in 5th International Forum on. Aluminum Ships pp. 1-10, (2005)

2. H.E. Jaeger, Aluminium in Shipbuilding, Int. Shipbuild. Prog., 1955, 2(11), p 319-350

3. A. D. Maimon, On the Use of Aluminium in Shipbuilding, Ann. "Dunarea Jos" Univ. Galati, FASCICLE XI - Shipbuild. pp. 123-130 (2015)

4. S. Gupta, D. Singh, A. Yadav, S. Jain, and B. Pratap, A Comparative Study of 5083 Aluminium Alloy and 316L Stainless Steel for Shipbuilding Material, Mater. Today Proc., 2020, 28, p 2358-2363

5. R. Kapoor, Severe Plastic Deformation of Materials, in Materials Under Extreme Conditions: Recent Trends and Future Prospects (2017) pp. 717-754

6. I. Sabirov, M.Y. Murashkin, and R.Z. Valiev, Nanostructured Aluminium Alloys Produced by Severe Plastic Deformation: New Horizons in Development, Mater. Sci. Eng. A, 2013, 560, p 1-24

7. R.Z. Valiev, R.K. Islamgaliev, and I.V. Alexandrov, Bulk Nanostructured Materials from Severe Plastic Deformation, Prog. Mater. Sci., 2000, 45(2), p 103-189

8. R.Z. Valiev, Y. Estrin, Z. Horita, T.G. Langdon, M.J. Zehetbauer, and Y.T. Zhu, Fundamentals of Superior Properties in Bulk NanoSPD Materials, Mater. Res. Lett., 2016, 4(1), p 1-21

9. J. Zhang, M.J. Starink, N. Gao, and W. Zhou, Effect of Mg Addition on Strengthening of Aluminium Alloys Subjected to Different Strain Paths in High Pressure Torsion, Mater. Sci. Eng. A, 2011, 528(4-5), p $2093-$ 2099

10. Y. Liu et al., Effect of Mg on Microstructure and Mechanical Properties of Al-Mg Alloys Produced by High Pressure Torsion, Scr. Mater, 2019, 159, p 137-141

11. L. Tang, X. Peng, J. Huang, A. Ma, Y. Deng, and G. Xu, Microstructure and Mechanical Properties of Severely Deformed Al$\mathrm{Mg}-\mathrm{Sc}-\mathrm{Zr}$ Alloy and their Evolution During Annealing, Mater. Sci. Eng. A, 2019, 754, p 295-308

12. S.Y. Chang, B. Du Ahn, S.K. Hong, S. Kamado, Y. Kojima, and D.H. Shin, Tensile Deformation Characteristics of a Nano-structured 5083 Al Alloy, J. Alloys Compd., 2005, 386(1-2), p 197-201

13. I.A. Ovid'ko, R.Z. Valiev, and Y.T. Zhu, Review on Superior Strength and Enhanced Ductility of Metallic Nanomaterials, Prog. Mater. Sci., 2018, 94, p 462-540

14. B. Zou, Z.Q. Chen, C.H. Liu, and J.H. Chen, Microstructure Evolution of Heavily Deformed AA5083 Al-Mg Alloy Studied by Positron Annihilation Spectroscopy, Appl. Surf. Sci., 2014, 296, p 154-157

15. R. Král, and P. Lukáč, Modelling of Strain Hardening and its Relation to the Onset of Portevin-Le Chatelier Effect in Al-Mg Alloys, Mater. Sci. Eng. A, 1997, 234-236(97), p 786-789

16. M. Richert, J. Richert, J. Zasadziński, S. Hawryłkiewicz, and J. Długopolski, Effect of Large Deformations on the Microstructure of Aluminium Alloys, Mater. Chem. Phys., 2003, 81(2-3), p 528-530

17 P.B. Prangnell, J.R. Bowen, and P.J. Apps, Ultra-fine Grain Structures in Aluminium Alloys by Severe Deformation Processing, Mater. Sci. Eng. A, 2004, 375-377(1-2), p 178-185

18. R.Z. Valiev, N.A. Enikeev, and T.G. Langdon, Towards Superstrength of Nanostructured Metals and Alloys, Produced by SPD, Kov. Mater., 2011, 49(1), p 1-9

19. H. Wang, H. Geng, D. Zhou, K. Niitsu, O. Muránsky, and D. Zhang, Multiple Strengthening Mechanisms in High Strength UltrafineGrained Al-Mg Alloys, Mater. Sci. Eng. A, 2019, 771(May), p 2020

20 H. Garbacz, K. Topolski and M. Motyka, Hydrostatic Extrusion, Elsevier Inc., 2018

21. Z. Pakieła et al., Structure and Properties of Nanomaterials Produced by Severe Plastic Deformation, Nukleonika, 2006, 51(SUPPL. 1), p $19-25$

22. M. Kulczyk, J. Skiba, and W. Pachla, Microstructure and Mechanical Properties of AA5483 After Combination of ECAP and Hydrostatic Extrusion SPD Processes, Arch. Metall. Mater., 2014, 59(1), p 6-9

23 Z. Pakiela, K. Ludwichowska, J. Ferenc, and M. Kulczyk, Mechanical Properties and Electrical Conductivity of Al 6101 and 6201 Alloys Processed by Hydro-Extrusion, IOP Conf. Ser. Mater. Sci. Eng., 2014, 63(1), p 012120 
24. M. Kulczyk, S. Przybysz, J. Skiba, and W. Pachla, Severe Plastic Deformation Induced in $\mathrm{Al}, \mathrm{Al}-\mathrm{Si}, \mathrm{Ag}$ and $\mathrm{Cu}$ by Hydrostatic Extrusion, Arch. Metall. Mater., 2014, 59(1), p 59-64

25. J. Zdunek, B. Adamczyk-Cieslak, M. Koralnik, M. Kulczyk, and J. Mizera, The Influence of Combined Hydrostatic Extrusion and Rolling on the Microstructure, Texture and Mechanical Properties of Al-Li Alloys, J. Manuf. Process., 2019, 47(April 2018), p 254-262

26 K. Majchrowicz, Z. Pakieła, W. Chrominski, and M. Kulczyk, Enhanced Strength and Electrical Conductivity of Ultrafine-Grained Al-Mg-Si Alloy Processed by Hydrostatic Extrusion, Mater. Charact., 2018, 135(May 2017), p 104-114

27. P. Widlicki, H. Garbacz, M. Lewandowska, W. Pachla, M. Kulczyk, and K.J. Kurzydlowski, The Influence of Hydrostatic Extrusion on the Microstructure of 6082 Aluminium Alloy, Solid State Phenom., 2006, 114, p 145-150

28. P. Widlicki, H. Garbacz, M. Lewandowska, W. Pachla, and K. J. Kurzydlowski, Microstructure and Mechanical Properties of 6082 Aluminum Alloy Processed by Hydrostatic Extrusion, In Nanostructured Materials by High-Pressure Severe Plastic Deformation (2006) pp. $175-180$

29. M. Lewandowska, and K.J. Kurzydlowski, Recent Development in Grain Refinement by Hydrostatic Extrusion, J. Mater. Sci., 2008, 43(23-24), p 7299-7306

30 K.J. Kurzydlowski, and M. Lewandowska, Fabrication of Nanostructured Materials by Hydrostatic Extrusion: Advantages and Limitations, Mater. Sci. Forum, 2007, 561-565(2), p 913-916

31. J. Gilbert Kaufman, Introduction to Aluminum Alloys and Tempers, ASM International, 2000

32. N.Y. Zolotorevsky, A.N. Solonin, A.Y. Churyumov, and V.S. Zolotorevsky, Study of Work Hardening of Quenched and Naturally Aged Al-Mg and Al-Cu Alloys, Mater. Sci. Eng. A, 2009, 502(1-2), p 111117

33. Ø. Ryen, O. Nijs, E. Sjölander, B. Holmedal, H.E. Ekström, and E. Nes, Strengthening Mechanisms in Solid Solution Aluminum Alloys, Metall. Mater. Trans. A Phys. Metall. Mater. Sci., 2006, 37(6), p 19992006

34. M.P. Liu et al., Structure and Mechanical Properties of Nanostructured Al-Mg Alloys Processed by Severe Plastic Deformation, J. Mater. Sci., 2013, 48(13), p 4681-4688

35. L. Lu, T. Liu, S. Jiang, F. Pan, Q. Liu, and Z. Wang, Microstructure and Mechanical Property of Dual-Directional-Extruded Mg Alloy AZ31, Mater. Sci. Eng. A, 2010, 527(16-17), p 4050-4055
36. A. Korbel, J.D. Embury, M. Hatherly, P.L. Martin, and H.W. Erbsloh, Microstructural Aspects of Strain Localization in AlMg Alloys, Acta Metall., 1986, 34(10), p 1999-2009

37. Y. Birol, Effect of Solute Mg on Grain Size of Aluminium Alloys, Mater. Sci. Technol. (United Kingdom), 2012, 28(8), p 924-927

38. T. Morishige, T. Hirata, T. Uesugi, Y. Takigawa, M. Tsujikawa, and K. Higashi, Effect of Mg Content on the Minimum Grain Size of Al-Mg Alloys Obtained by Friction Stir Processing, Scr. Mater, 2011, 64(4), p 355-358

39. J. Wang et al., An Investigation of Microstructural Stability in an A1Mg Alloy with Submicrometer Grain Size, Acta Mater., 1996, 44(7), p 2973-2982

40. M. Bournane, M. Nedjar, and A.F. Sirenko, Precipitation in Solid Solutions of Al-Mg, Scr. Mater, 1999, 40(3), p 375-382

41. F. Barlat, M.V. Glazov, J.C. Brem, and D.J. Lege, A Simple Model for Dislocation Behavior, Strain and Strain Rate Hardening Evolution in Deforming Aluminum Alloys, Int. J. Plast., 2002, 18(7), p 919-939

42. M. Muzyk, Z. Pakiela, and K.J. Kurzydlowski, Ab initio Calculations of the Generalized Stacking Fault Energy in Aluminium Alloys, Scr. Mater., 2011, 64(9), p 916-918

43. M.A. Kearns, and P.S. Cooper, Effects of Solutes on Grain Refinement of Selected Wrought Aluminium Alloys, Mater. Sci. Technol., 1997, 13(8), p 650-654

44 J. Gubicza, N.Q. Chinh, Z. Horita, and T.G. Langdon, Effect of Mg Addition on Microstructure and Mechanical Properties of Aluminum, Mater. Sci. Eng. A, 2004, 387-389(1-2), p 55-59

45. W. Wen, Y. Zhao, and J.G. Morris, The Effect of Mg Precipitation on The Mechanical Properties Of 5xxx Aluminum Alloys, Mater. Sci. Eng. $A, 2005$, 392(1-2), p 136-144

46. J. Zdunek, P. Widlicki, H. Garbacz, J. Mizera and K.J. Kurzydlowski, Influence of severe plastic deformation on the PLC effect and mechanical properties in Al 5XXX alloy, Solid State Phenom., 2006, 114, p 171-176

47. M. Liu et al., Grain Refinement in Nanostructured Al-Mg Alloys Subjected to High Pressure Torsion, J. Mater. Sci., 2010, 45(17), p 4659-4664

48 W. Pachla et al., Mechanical Properties and Microstructure of Ultrafine Grained Commercial Purity Aluminium Prepared by Cryo-Hydrostatic Extrusion, Mater. Sci. Eng. A, 2017, 695(December 2016), p 178-192

Publisher's Note Springer Nature remains neutral with regard to jurisdictional claims in published maps and institutional affiliations. 